\title{
BMJ Open How patients with COVID-19 managed the disease at home during the first wave in Spain: a cross-sectional study
}

María Romay-Barja (10 , ${ }^{1,2}$ Mario Pascual-Carrasco, ${ }^{3}$ María José De Tena-Dávila, ${ }^{3}$ María Falcón, ${ }^{4}$ Carmen Rodriguez-Blazquez, ${ }^{5}$ Maria João Forjaz,, ${ }^{5,6}$ Alba Ayala,,${ }^{6,7}$ Irene Molina-de la Fuente, ${ }^{1,8}$ Alfredo Burgos, ${ }^{3}$ Adolfo Muñoz, ${ }^{3}$ Agustin Benito ${ }^{1,2}$

To cite: Romay-Barja M, Pascual-Carrasco M, De TenaDávila MJ, et al. How patients with COVID-19 managed the disease at home during the first wave in Spain: a crosssectional study. BMJ Open 2021;11:e048702. doi:10.1136/ bmjopen-2021-048702

- Prepublication history and additional supplemental material for this paper are available online. To view these files, please visit the journal online (http://dx.doi.org/10.1136/ bmjopen-2021-048702).

Received 05 January 2021 Revised 09 April 2021 Accepted 29 April 2021
Check for updates

(c) Author(s) (or their employer(s)) 2021. Re-use permitted under CC BY-NC. No commercial re-use. See rights and permissions. Published by BMJ.

For numbered affiliations see end of article.

Correspondence to Dr María Romay-Barja; mromay@isciii.es

\section{ABSTRACT}

Objective Most patients with mild COVID-19 had to stay at home trying to implement an optimal quarantine. The aim of this study was to describe the COVID-19 cases during the first wave of the pandemic in Spain, how they managed the disease at home, focusing on differences by age, as well as differences in knowledge, attitudes and preventive practices, compared with the uninfected population.

Design An online survey was used to conduct a crosssectional study of individuals who were 14 years or older living in Spain during the COVID-19 lockdown. The main variable was a COVID-19 case. Logistic regression models for COVID-19 cases were obtained using a backward stepwise procedure to assess the association between social variables, disease knowledge, attitudes, prevention practices and emotional impact.

Results 3398 people completed the survey. Participants' mean age was 49.6 (SD=14.3). COVID-19 was significantly more prevalent among married people $(5.3 \%)$ and those currently doing an on-site work (8.7\%). Most of the COVID-19 cases stayed at home (84.0\%) during the episode. There were significant age-based differences with regard to self-isolation conditions at home during the disease. COVID-19 cases showed better attitudes, practices and knowledge about disease symptoms and transmission than the uninfected population. COVID-19 cases also felt more depressed (adjusted OR: 3.46, 95\% $\mathrm{Cl} 1.45$ to 8.26 ) and had better preventive behaviour than the uninfected population, such as always wearing a mask outside the home (adjusted OR 1.58, 95\% CI 1.06 to 2.30). Conclusion COVID-19 cases found it difficult to comply with recommended home self-isolation conditions, with differences by age group. COVID-19 had an important impact on care dependency in non-hospitalised patients, who were mostly dependent on their families for care. It is necessary to reinforce social and health services and to be ready to meet the care needs of populations during the different waves or in future epidemics.

\section{INTRODUCTION}

The SARS-CoV-2 coronavirus ${ }^{1}$ is a new virus from the Coronaviridae family identified in December 2019 in Wuhan (China) ${ }^{2}$ which causes COVID-19. ${ }^{3}$ The epidemic caused by this virus has spread worldwide, and

\section{Strengths and limitations of this study}

- The study obtained a large sample in the shortest time possible and provides valuable information on how patients with COVID-19 managed the disease at home during the lockdown.

- The study also addressed populations' knowledge, attitudes and practices 2 months after the COVID-19 outbreak.

- COVID-19 prevalence was consistent with the national seroprevalence study.

- Most survey respondents were highly educated people and this may affect the generalisability of the study.

- COVID-19 cases are based on the diagnosis reported by the respondents.

on 11 March 2020 the WHO declared it a pandemic. ${ }^{4}$ Although most patients have mild symptoms and good prognosis after infection, some develop severe forms and die within a few days, mainly due to adult respiratory distress syndrome and/or multiorgan dysfunction syndrome. ${ }^{5}$ The risk of developing severe disease is higher in older people and in people of all ages with pre-existing medical conditions. ${ }^{4}$ Age significantly determines the clinical features and prognosis of COVID-19, and older patients with COVID-19 are at an increased risk of death. ${ }^{6}$

Spain was one of the European countries most severely affected by the ongoing COVID-19 pandemic. On 14 March, the Spanish government decreed a state of emergency which lasted until 21 June 2020. This unprecedented measure included a national lockdown, with most of the population confined to home, and for more than 2 months only essential services were operational. ${ }^{7}$ By the end of April, 45 days after the general lockdown, Spain had more than 203 000 confirmed cases, 105548 recovered patients and almost 16000 deaths $^{8} ; 46 \%$ of confirmed cases were hospitalised and $86 \%$ of deaths were 
Table 1 Sociodemographic characteristics by COVID-19 cases

\begin{tabular}{|c|c|c|c|c|c|c|c|}
\hline & Total & & Covl & ases & & & \\
\hline & $\mathbf{n}$ & $\%$ & No & $\%$ & Yes & $\%$ & $P$ value \\
\hline Sex & & & & & & & 0.343 \\
\hline Male & 1093 & 32.2 & 1035 & 94.7 & 58 & 5.3 & \\
\hline Age (years) & & & & & & & 0.234 \\
\hline $30-44$ & 698 & 20.5 & 657 & 94.1 & 41 & 5.9 & \\
\hline $45-59$ & 1427 & 42.0 & 1356 & 95.0 & 71 & 5.0 & \\
\hline$\geq 60$ & 862 & 25.4 & 830 & 96.3 & 32 & 3.7 & \\
\hline Marital status & & & & & & & 0.026 \\
\hline With a partner & 2286 & 67.3 & 2164 & 94.7 & 122 & 5.3 & \\
\hline Secondary & 660 & 19.4 & 631 & 95.6 & 29 & 4.4 & \\
\hline University & 2640 & 77.7 & 2514 & 95.2 & 126 & 4.8 & \\
\hline Type of house & & & & & & & 0.358 \\
\hline Flat & 2521 & 74.2 & 2406 & 95.4 & 115 & 4.6 & \\
\hline Other & 877 & 25.8 & 830 & 94.6 & 47 & 5.4 & \\
\hline Are you currently working? & & & & & & & $<0.001$ \\
\hline No & 1386 & 40.8 & 1345 & 97.0 & 41 & 3.0 & \\
\hline Yes & 2012 & 59.2 & 1891 & 94.0 & 121 & 6.0 & \\
\hline Bad, very bad & 71 & 2.1 & 67 & 94.4 & 4 & 5.6 & \\
\hline
\end{tabular}

people over 70 years of age. According to a national seroepidemiological study carried out between 27 April and 11 May, the prevalence of coronavirus in Spain was 5\% $(95 \%$ CI 4.7 to 5.4$)$; however, majority of cases $(90 \%)$ remained, at that time, without confirmatory diagnosis. ${ }^{9}$ The country was considered to be in scenario 4 in terms of progression of the COVID-19 outbreak, ${ }^{10}$ with sustained community transmission, saturated intensive care capacity and an overwhelmed healthcare system. Worldwide the pandemic has led to an unprecedented reliance on home care as pillar of the healthcare system to support people with confirmed or suspected of COVID-19. ${ }^{11}$ Patients and caregivers were counselled on how to prevent household transmission and how to adequately implement home isolation measures ${ }^{12}$; however, not all were able to follow these measures. ${ }^{13}$

Certain social barriers need to be considered before discharging patients with COVID-19 to their home, including housing challenges, inability to safely quarantine in a crowded, small or multifamily dwelling, patient and family anxiety, and financial constraints. ${ }^{14}$ One study in Spain assessed individuals' self-efficacy in adopting preventive measures, including home management of patients with mild COVID-19 symptoms, and reported high efficacy in COVID-19 prevention, symptom recognition and home management. ${ }^{15}$ However, little is known about how patients with COVID-19 have managed the disease at home, the support they have received and if they managed to follow self-isolation recommendations to avoid infecting the rest of their family. More research is necessary to design optimal case isolation strategies and to protect household contacts. ${ }^{16}$

A pandemic like COVID-19 called for rapid assessments of the population's knowledge, risk perceptions and related behaviours in order to improve public health response. ${ }^{17}$ Population-representative household surveys generally involve many months of preparation and data collection, $^{18}$ which is why quick online surveys have become a valuable tool to assess knowledge, attitudes 
Table 2 COVID-19 cases by age

\begin{tabular}{|c|c|c|c|c|c|c|c|c|c|}
\hline Age & 14-29 & $\%$ & $30-44$ & $\%$ & 45-59 & $\%$ & $\geq 60$ & $\%$ & $P$ value \\
\hline \multicolumn{9}{|c|}{ Did you have any confirmed test or PCR done? } & 0.611 \\
\hline No & 7 & 38.9 & 24 & 58.5 & 36 & 50.7 & 15 & 46.9 & \\
\hline Yes, later & 6 & 33.3 & 8 & 19.5 & 16 & 22.5 & 5 & 15.6 & \\
\hline \multicolumn{9}{|c|}{ Where did you stay when you were ill? } & 0.060 \\
\hline At hospital and at home & 0 & 0.0 & 0 & 0.0 & 5 & 7.0 & 6 & 18.8 & \\
\hline At home & 18 & 100.0 & 36 & 87.8 & 59 & 83.1 & 23 & 71.9 & \\
\hline Having normal life & 0 & 0.0 & 5 & 12.2 & 5 & 7.0 & 2 & 6.3 & \\
\hline \multicolumn{9}{|c|}{ Were you prescribed any treatment to take at home? } & $<0.001$ \\
\hline Paracetamol & 8 & 44.4 & 26 & 63.4 & 47 & 66.2 & 17 & 53.1 & \\
\hline \multicolumn{9}{|c|}{ Do you feel completely cured? } & 0.132 \\
\hline Yes & 16 & 88.9 & 33 & 80.5 & 58 & 81.7 & 29 & 90.6 & \\
\hline No & 2 & 11.1 & 8 & 19.5 & 13 & 18.3 & 3 & 9.4 & \\
\hline
\end{tabular}

and practices in the midst of an outbreak. ${ }^{19}$ Since the COVID-19 pandemic began, several countries have conducted studies on population behaviour in preventing and controlling the disease during the pandemic in order to help and guide authorities in designing evidence-based messages and measures. Surveys on knowledge, attitudes and preventive practices (KAP) help to inform many outbreak responses. ${ }^{2021}$

The aim of this study was to describe the cases of COVID-19 during the first wave of the pandemic in Spain, how they managed the disease at home, focusing on differences by age, as well as differences in KAP, compared with the uninfected population. This study provides valuable information that could reinforce approaches intended to support patients in dealing with the disease at home.

\section{METHODS}

\section{Sampling and data collection}

A descriptive cross-sectional study was designed to determine the KAP of the general population and COVID-19 cases and assess their response to the disease and the public health measures implemented in Spain during the first wave and the lockdown.

Resident populations of Spain were invited to participate in the online survey. A non-probabilistic method using a snowball sampling technique was used to select the participants. Inclusion criteria were age 14 years or older and living in Spain during the lockdown. The survey was posted on RICET (National Research Network of Tropical Medicine) web page (https://www.ricet.es/noticias/encuesta-ricet-COVID-19) and was accessed through WhatsApp via a standard message inviting the population to participate and encouraging them to share the survey with their contacts. After sending these first messages, the survey was open for 24 hours. According to the National Survey on the Equipment and Use of Information and Communication Technologies in Households, WhatsApp was the most highly used instant messaging service in 2020 , and almost $90 \%$ of the Spanish population between 16 and 74 years of age used it. ${ }^{22}$ Respondents were informed about the aims of the study and signed their participation consent by agreeing to complete the questionnaire. Assuming an error margin of $3 \%$, a confidence level of $95 \%$ and a $50 \%$ response rate, a minimum of 1068 participants were required. A total of 4919 surveys were recorded, of which 3398 were completed questionnaires.

Participation was anonymous. The survey included questions about socioeconomic characteristics (sex, age, marital status, level of education, work activity and type of work), respondents' health status before the lockdown, COVID-19 knowledge (disease symptoms, forms of transmission and prevention measures), attitudes (disease severity perception), emotional impact (concern about the disease and psychological feelings) and preventive practices they had implemented since the lockdown (see online supplemental file). The questionnaire also addressed issues specific to COVID-19 cases, such as diagnostic process, treatment administered, duration of symptoms, home isolation conditions and suspected place of infection. COVID-19 cases were defined as endorsing the question 'Have you had coronavirus or COVID-19?' coded in three categories: yes, no and I don't know.

Telematics resources already available at the Instituto de Salud Carlos III provided the technological support 


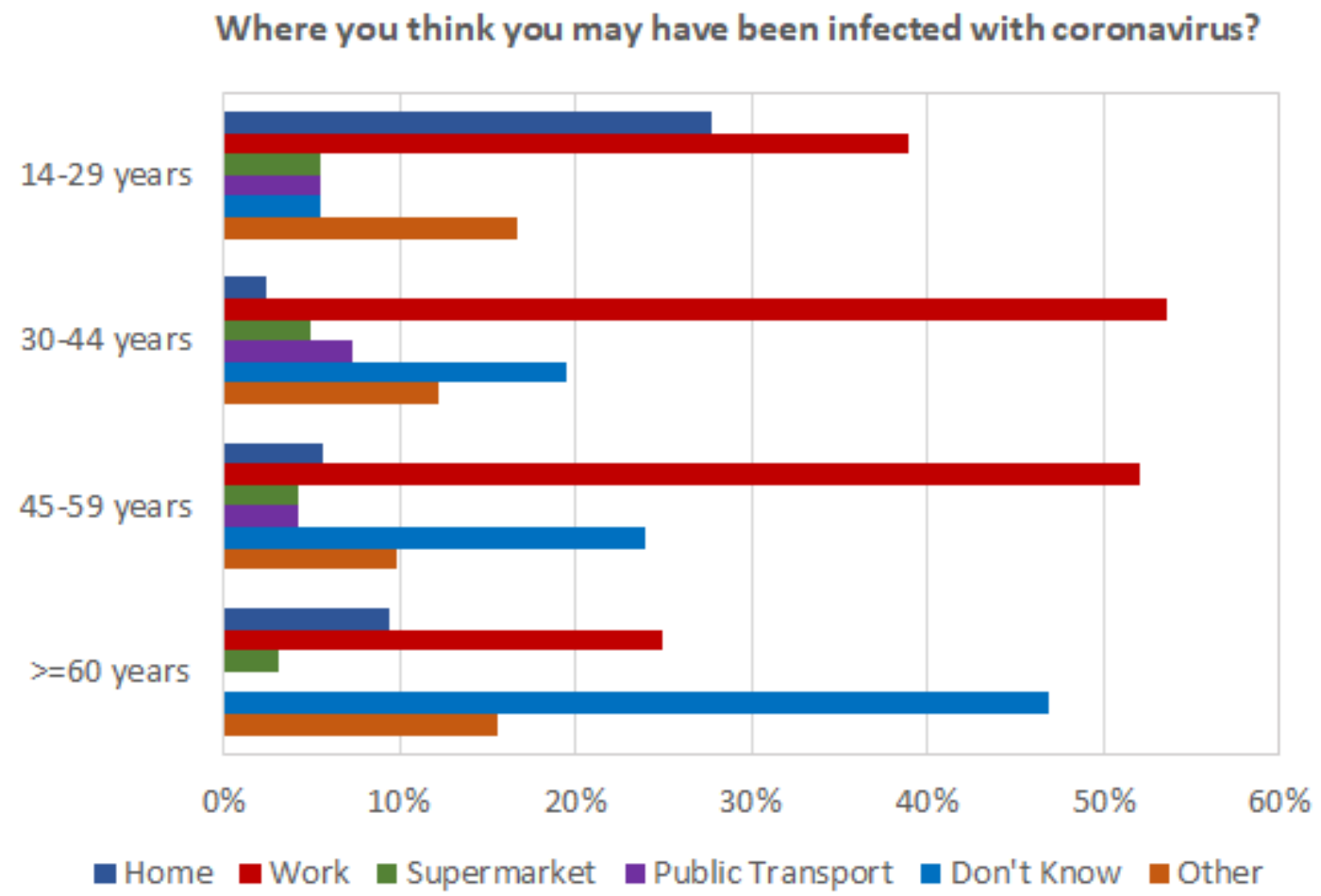

Figure 1 Reported place of infection by age.

needed to develop and deploy the survey. The survey was implemented with standard technologies so that it could be viewed on all types of personal devices (personal computer, tablet, smartphone) with LimeSurvey, an open-source software tool. Information was exchanged and processed in accordance with current data protection regulation.

\section{Data analyses}

Descriptive statistics were applied to all variables. Frequencies and percentages were used to summarise data and to assess factors related to COVID-19. $\chi^{2}$ tests for categorical variables were also performed. Mean and SD were calculated for age as a continuous variable. COVID-19 cases were recoded as yes and no (including don't know respondents). Bivariate analysis of the associations between the independent variables and COVID-19 cases was conducted using simple logistic regression. Independent variables that were significantly associated with COVID-19 cases at the level of $\mathrm{p}<0.05$, as well as age, were included in the multivariable analysis. Logistic regression models for COVID-19 cases were obtained using a backward stepwise procedure. Adjusted OR and 95\% CI were computed, and $\mathrm{p}$ values less than or equal to 0.05 were considered statistically significant in all analyses. Data analysis was performed using SPSS V.25 software.

\section{Patient and public involvement}

Both the research team and the participants contributed to recruitment and dissemination of the online survey.

\section{RESULTS}

\section{Descriptive statistics}

Participants' mean age was 49.6 ( $\mathrm{SD}=14.3), 67.8 \%$ were female and $52.9 \%$ were married. In terms of educational background $77.7 \%$ had reached university and $56.7 \%$ were teleworking.

With regard to prevalence of COVID-19, out of a total of 3398 participants in the study, 162 (4.8\%) reported having COVID-19 during the first wave of the coronavirus epidemic in Spain (table 1). COVID-19 was more prevalent among married people or with a partner $(5.3 \%)$ and those currently doing an on-site work $(8.7 \%)$ compared with their counterparts $(\mathrm{p}<0.001)$.

\section{COVID-19 case management}

Almost half of positive cases (49.4\%) had confirmed diagnosis through PCR or different tests. Among these, only $56.3 \%$ had a laboratory diagnosis at the beginning of their symptoms, while $43.8 \%$ of cases had confirmed diagnosis after recovery. Most of the cases between 30 and 44 years (58.5\%) never had a confirmed diagnosis, while people 60 years and older were more frequently diagnosed at the 
beginning of their symptoms, although differences were not statistically significant (table 2).

According to patients, most of the COVID-19 cases stayed at home $(84.0 \%)$; only $1.9 \%$ were hospitalised, mainly people over 45 years old, and $6.9 \%$ were hospitalised first and then sent home as soon as their symptomatology improved. All patients under 30 years old stayed at home during the disease episode. Also 7.4\% of COVID-19 cases said they had led a 'normal life' because they were ill before the lockdown and were not aware that they had COVID-19. The median days with symptomatology was 16 , ranging from 0 to 50 , and without significant differences by age.

The most prescribed treatments at home were paracetamol $(60.5 \%)$, antibiotics $(14.8 \%)$ and hydroxychloroquine $(6.2 \%)$, with significant differences by age. Having no treatment at all was more frequent among young cases (between 14 and 29 years), while hydroxychloroquine and antibiotics were the most prescribed treatments in older patients (above 60 years of age). When asked if they feel completely cured, $16.0 \%$ said they do not feel recovered yet, with no significant differences by age.

With regard to place of infection, half of the cases believe they got infected at work $(45.6 \%)$, with significant differences by age $(p=0.022)$ (figure 1$)$. While half of the cases under 25 years old said they were infected at home $(50.0 \%)$, most cases aged between 30 and 59 years said they got infected at work $(59.9 \%)$ and most patients over 70 years old $(72.7 \%)$ did not know where they got infected.

There were significant differences by age with regard to compliance with home self-isolation conditions during the disease: $27.1 \%$ of cases had to share their bedroom and cases between 30 and 59 years old were the ones least able to self-isolate $(\mathrm{p}=0.010) ; 43.1 \%$ of cases who had to share bathroom were more frequently the oldest $(\mathrm{p}=0.015)$. When asked about the support received during the disease, $36.8 \%$ of the patients did not receive any help with cleaning the house and $24.3 \%$ did not receive any help with cooking during the episode of COVID19. However, most of those under 29 years old $(94.1 \%)$ reported having received help (figure 2).

\section{Knowledge, attitudes and preventive practices}

With regard to knowledge about COVID-19 symptoms, fever was the symptom most mentioned in general, while cough, fatigue, body pain and diarrhoea were mentioned by COVID-19 cases significantly more as potential symptoms (table 3). Also, transmission of coronavirus through 'physical contact with someone infected' was mentioned significantly more by COVID-19 cases than by uninfected people.

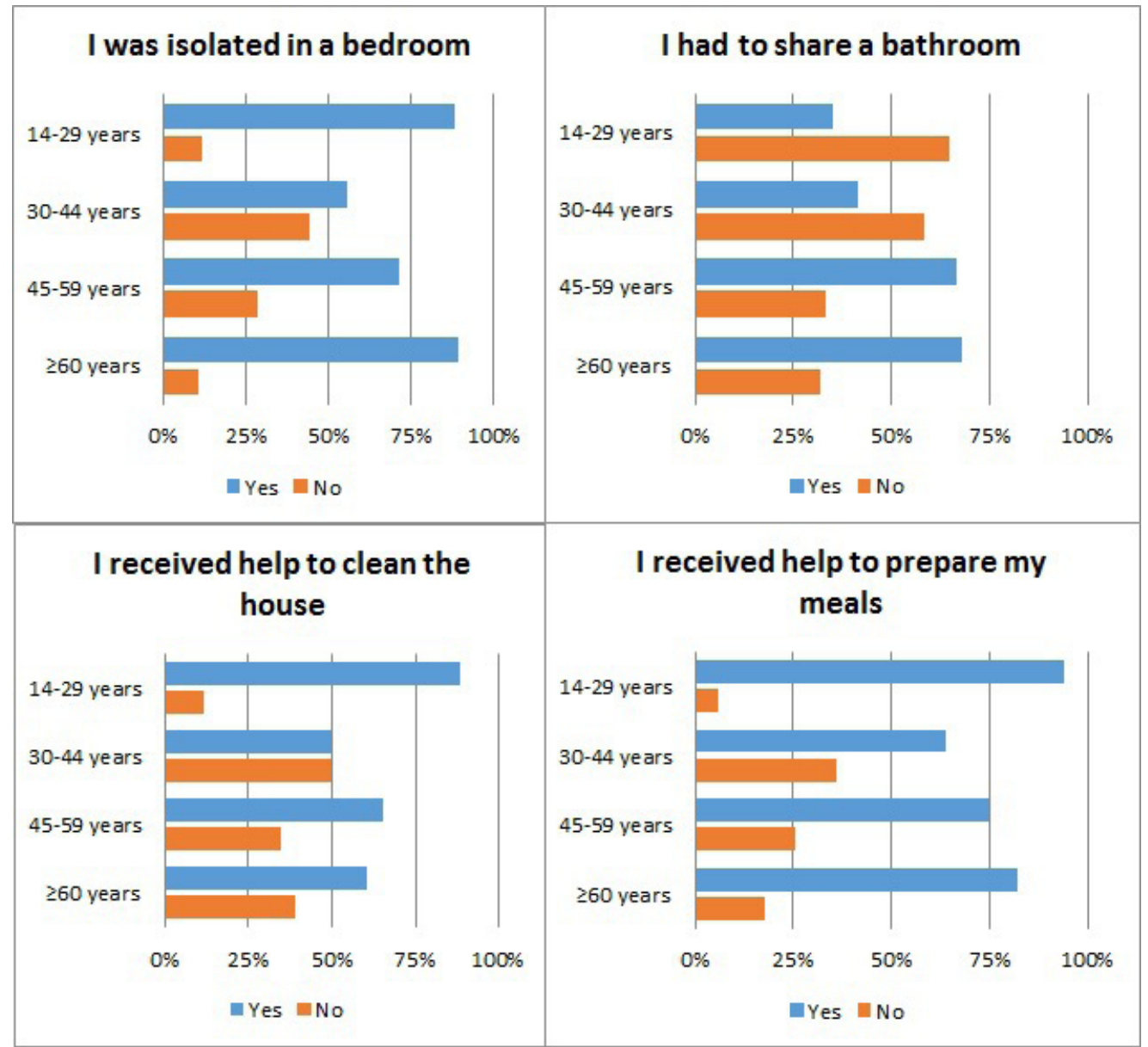

Figure 2 Home conditions of COVID-19 cases by age. 
Table 3 COVID-19-related knowledge, attitudes and preventive behaviour during the first wave in Spain

\begin{tabular}{|c|c|c|c|c|c|}
\hline \multirow[b]{3}{*}{ Knowledge } & \multicolumn{4}{|c|}{ COVID-19 case } & \multirow[b]{3}{*}{$P$ value } \\
\hline & \multicolumn{2}{|c|}{ No } & \multicolumn{2}{|l|}{ Yes } & \\
\hline & $\mathbf{n}$ & $\%$ & $\mathbf{n}$ & $\%$ & \\
\hline \multicolumn{6}{|l|}{ Main symptoms* } \\
\hline Fever & 3195 & 98.7 & 161 & 99.4 & 0.397 \\
\hline Cough & 3105 & 96.0 & 161 & 99.4 & 0.011 \\
\hline Fatigue & 2282 & 70.5 & 141 & 87.0 & $<0.001$ \\
\hline Body pain & 2007 & 62.0 & 127 & 78.4 & $<0.001$ \\
\hline Respiratory distress & 2964 & 91.6 & 150 & 92.6 & 0.394 \\
\hline Diarrhoea & 1407 & 43.5 & 98 & 60.5 & $<0.001$ \\
\hline \multicolumn{6}{|l|}{ Transmission* } \\
\hline Drops when coughing or speaking & 3189 & 98.6 & 161 & 99.4 & 0.324 \\
\hline Contaminated surfaces & 2898 & 89.6 & 141 & 87.0 & 0.186 \\
\hline Physical contact with someone infected & 2490 & 77.0 & 138 & 85.2 & 0.007 \\
\hline Through pets & 3174 & 98.3 & 165 & 96.3 & 0.068 \\
\hline \multicolumn{6}{|l|}{ Prevention measures ${ }^{*}$} \\
\hline Wear a mask & 2754 & 85.1 & 141 & 87.0 & 0.293 \\
\hline Wash your hands frequently & 3214 & 99.3 & 161 & 99.4 & 0.699 \\
\hline Clean surfaces frequently & 2741 & 84.7 & 143 & 88.3 & 0.129 \\
\hline Stay at home & 2061 & 63.7 & 97 & 59.9 & 0.184 \\
\hline $\begin{array}{l}\text { Cover your mouth and nose with your bent elbow or tissue when you } \\
\text { cough or sneeze }\end{array}$ & 2807 & 86.7 & 146 & 90.1 & 0.128 \\
\hline Keep a distance of 2 metres & 3045 & 94.1 & 150 & 92.6 & 0.259 \\
\hline \multicolumn{6}{|l|}{ Attitudes } \\
\hline You think the coronavirus is a disease that is... & & & & & 0.347 \\
\hline Mild & 35 & 1.1 & 4 & 2.5 & \\
\hline Moderate & 509 & 15.7 & 26 & 16.1 & \\
\hline Severe & 1514 & 46.8 & 79 & 48.8 & \\
\hline Very severe & 1178 & 36.4 & 53 & 32.7 & \\
\hline \multicolumn{6}{|l|}{ Emotional impact } \\
\hline How worried are you about COVID-19? & & & & & 0.453 \\
\hline Not at all & 15 & 0.5 & 1 & 0.6 & \\
\hline A little & 284 & 8.8 & 12 & 7.4 & \\
\hline Quite & 956 & 29.5 & 43 & 26.5 & \\
\hline Very worried & 1154 & 35.7 & 54 & 33.3 & \\
\hline Extremely & 827 & 25.6 & 52 & 32.1 & \\
\hline In the last 2 weeks, you felt depressed... & & & & & 0.010 \\
\hline Never & 886 & 27.4 & 35 & 21.6 & \\
\hline Once & 426 & 13.2 & 19 & 11.7 & \\
\hline Sometimes & 1673 & 51.7 & 90 & 55.6 & \\
\hline Once a day & 145 & 4.5 & 5 & 3.1 & \\
\hline Always & 106 & 3.3 & 13 & 8.0 & \\
\hline \multicolumn{6}{|l|}{ Preventive behaviour } \\
\hline \multicolumn{6}{|l|}{ During the lockdown you have... } \\
\hline Washed your hands frequently & 3113 & 96.2 & 153 & 94.4 & 0.176 \\
\hline Kept distance of 2 metres & 3095 & 95.6 & 151 & 93.2 & 0.107 \\
\hline
\end{tabular}




\begin{tabular}{|c|c|c|c|c|c|}
\hline \multirow[b]{3}{*}{ Knowledge } & \multicolumn{4}{|c|}{ COVID-19 case } & \multirow[b]{3}{*}{$P$ value } \\
\hline & \multicolumn{2}{|l|}{ No } & \multicolumn{2}{|l|}{ Yes } & \\
\hline & $\mathbf{n}$ & $\%$ & $\mathbf{n}$ & $\%$ & \\
\hline Kept shoes at the entrance of the house & 2080 & 64.3 & 97 & 60.0 & 0.275 \\
\hline Cleaned knobs and switches frequently & 1416 & 43.8 & 98 & 60.5 & $<0.001$ \\
\hline \multicolumn{6}{|l|}{ Since the lockdown you wear a mask... } \\
\hline Always outside the home & 1630 & 50.4 & 108 & 66.7 & $<0.001$ \\
\hline At work & 591 & 18.3 & 46 & 28.4 & 0.001 \\
\hline Never & 226 & 7.0 & 5 & 3.1 & 0.030 \\
\hline \multicolumn{6}{|l|}{ Since the lockdown you wear gloves... } \\
\hline Never & 541 & 16.7 & 22 & 13.6 & 0.331 \\
\hline Since the lockdown you have left home... & & & & & $<0.001$ \\
\hline Every day & 510 & 15.8 & 28 & 17.3 & \\
\hline Time to time & 2262 & 69.9 & 91 & 56.2 & \\
\hline I have not been out since & 464 & 14.3 & 43 & 26.5 & \\
\hline
\end{tabular}

${ }^{*}$ Correct answers.

There were no significant attitude-based differences between cases and uninfected people, and COVID-19 was perceived as a severe or very severe disease by $83.1 \%$ of the population. Also, most of the surveyed population said their health status before the COVID-19 pandemic was good or very good $(78.7 \%)$. No significant differences in COVID-19 concern were found between cases and noncases, and $61.4 \%$ of the surveyed population reported being very or extremely worried about the COVID-19 pandemic. However, there were significant differences in terms of the emotional impact of the lockdown, and COVID-19 cases reported feeling depressed more often than non-cases.

Cases reported always wearing a mask when they leave home, cleaning the knobs and switches, and washing their clothes with hot water significantly more often than non-cases $(p<0.001)$. Cases also reported wearing gloves significantly more often than non-cases. While most of the population said they had sometimes gone out since the lockdown, cases reported not having been out since the start of the lockdown significantly more often than the uninfected population.

After adjusting for other variables (table 4), people who worked on-site had 2.5 odds of having had COVID-19 during the first wave of the pandemic in Spain. Also, knowing symptoms such as fatigue and how coronavirus is transmitted, was also associated with COVID-19 cases. With regard to the prevention measures implemented, COVID-19 cases washed clothes with hot water and always wore a mask outside their home significantly more than uninfected people. Cases also stayed at home during the lockdown 3.2 times more than uninfected people $(95 \%$ CI 1.72 to 5.99$)$ and felt depressed 3.4 times more frequently than the uninfected population (95\% CI 1.45 to 8.26 ).

\section{DISCUSSION}

This is the first study to describe how patients with COVID-19 managed the disease at home during the first wave of the coronavirus in Spain. Our study found statistically significant differences in prevalence according to sociodemographic characteristics. We also found differences in hospitalisation, disease diagnostic confirmation, treatment and home isolation conditions by age. There were also significant differences in knowledge, attitudes, emotional impact and preventive behaviour between cases and the uninfected population.

In concordance with a national seroepidemiological study, ${ }^{9}$ the prevalence of COVID-19 in our study was $4.8 \%$. As in other studies, the prevalence was significantly higher among those married or with a partner, ${ }^{23} 24$ as most have to share bedroom until the onset of symptoms, as well as among those currently doing on-site work. ${ }^{16}$ Almost $75 \%$ of cases were working during the lockdown and most of them were doing on-site work, meaning that they were working on essential jobs at that time and most of them were in contact with the general population and/or populations at risk. 
Table 4 Logistic regression of cases of COVID-19*

\begin{tabular}{|c|c|c|c|c|}
\hline \multirow[b]{2}{*}{ Variable (reference) } & \multicolumn{2}{|l|}{ Crude } & \multicolumn{2}{|l|}{ Adjusted } \\
\hline & OR $(95 \% \mathrm{Cl})$ & $P$ value & OR (95\% Cl) & $P$ value \\
\hline \multicolumn{5}{|l|}{ Marital status } \\
\hline Without partner (with partner) & 0.66 (0.46 to 0.95$)$ & 0.026 & & \\
\hline \multicolumn{5}{|l|}{ Type of work } \\
\hline Teleworking (on-site working) & 0.43 (0.29 to 0.63 ) & $<0.001$ & 0.39 (0.26 to 0.59$)$ & $<0.001$ \\
\hline \multicolumn{5}{|l|}{ Symptoms } \\
\hline Fatigue (no) & 2.81 (1.76 to 4.47$)$ & $<0.001$ & 2.50 (1.45 to 4.31$)$ & 0.001 \\
\hline Body pain (no) & 2.22 (1.52 to 3.25$)$ & $<0.001$ & & \\
\hline \multicolumn{5}{|l|}{ Transmission } \\
\hline Physical contact with someone infected (no) & 1.72 (1.11 to 2.68$)$ & 0.016 & 2.16 (1.25 to 3.72$)$ & 0.006 \\
\hline \multicolumn{5}{|l|}{ In the last 2 weeks, you have felt depressed... } \\
\hline (Never) & - & & - & \\
\hline Once & 1.13 (0.64 to 2.00$)$ & 0.677 & 1.51 (0.85 to 3.23$)$ & 0.137 \\
\hline Sometimes & 1.36 (0.91 to 2.03 ) & 0.129 & 1.61 (0.97 to 2.66$)$ & 0.066 \\
\hline Once a day & 0.87 (0.34 to 2.27$)$ & 0.780 & 1.57 (0.57 to 4.37$)$ & 0.384 \\
\hline All the time & 3.11 (1.59 to 6.05$)$ & 0.001 & 3.46 (1.45 to 8.26$)$ & 0.005 \\
\hline \multicolumn{5}{|l|}{ During the lockdown you have } \\
\hline Cleaned knobs and switches frequently (no) & 1.97 (1.43 to 2.72$)$ & $<0.001$ & & \\
\hline Washed clothes with hot water (no) & 2.01 (1.47 to 2.76$)$ & $<0.001$ & 1.56 (1.06 to 2.30$)$ & 0.025 \\
\hline \multicolumn{5}{|l|}{ Since the lockdown you wear a mask.... } \\
\hline Always outside the home (no) & 1.97 (1.41 to 2.75$)$ & $<0.001$ & 1.58 (1.06 to 2.30$)$ & 0.026 \\
\hline \multicolumn{5}{|l|}{ Since the lockdown you have left home.... } \\
\hline (Every day) & - & & - & \\
\hline Time to time & $0.73(0.47$ to 1.13$)$ & 1.161 & $1.37(0.82$ to 2.31$)$ & \\
\hline I have not been out since & 1.69 (1.03 to 2.76$)$ & 0.037 & 3.20 (1.72 to 5.98$)$ & $<0.001$ \\
\hline
\end{tabular}

*Only variables that stay in the model.

Half of the COVID-19 cases stayed at home without a confirmed diagnosis during the first wave of the epidemic in Spain. Since March, the healthcare system had been overwhelmed, and most of the hospital beds and all intensive care unit beds were used by patients with COVID-19. ${ }^{10}$ Primary care services were also overloaded and, as in many other countries, ${ }^{11}$ diagnoses were symptom-based and clinical management was done mainly by telephone.

It is broadly understood that age is one of the key determinants of COVID-19 symptom severity, ${ }^{26}{ }^{27}$ and our study found hospitalisations only in patients over 45 years of age. Also, in concordance with national reports, ${ }^{8}$ most cases in our study had mild or moderate conditions, and most reported having suffered COVID-19 at home and receiving only telematic medical care, especially the youngest ones. The oldest patients were treated most frequently with hydroxychloroquine and/or antibiotics, while paracetamol was the most prescribed treatment. However, one in every three cases did not receive any treatment. When the epidemic peaked in Spain, no targeted therapy was available, but a lot of drugs were being tested. Antipyretics, hydroxychloroquine and antibiotics were the treatments most frequently administered to mild cases at that time all over the world. ${ }^{5}$ The inefficacy of drugs like hydroxychloroquine in treating COVID-19 was demonstrated later. ${ }^{28}$

Place of infection also differed by age. Most of the cases between 30 and 59 years old believed they got infected at work, while younger cases said they got infected at home and older people did not know where they got infected. A case study performed in Italy showed a direct relationship between daily cases and mobility choices in the preceding 21 days. Thus, workers who could not telework from home, many of them doing unskilled labour, were more likely prone to high-risk exposure during the pandemic. ${ }^{29}$

The Spanish Ministry of Health's home self-isolation recommendations for mild COVID-19 cases were not to share bedroom or bathroom; however, total isolation was very difficult in most houses. According to our results, most of the cases were isolated in a bedroom but had to share bathroom, increasing the risk of infecting 
the rest of the family ${ }^{30}$ and increasing family stress by having to keep most home surfaces disinfected. Also, nearly a quarter of patients did not receive any help with cooking during their COVID-19 episode, except those under 29 years old (94.1\%). Experiences gained from previous epidemics have shown that individual and global nutrition must be kept at optimum levels in order to improve populations' physical and mental health. ${ }^{31}$ In Spain, food banks have seen a $60 \%$ average increase in users during the pandemic. ${ }^{32}$ Access to an adequate diet is influenced by multiple parameters such as socioeconomic status or neighbourhood environment. ${ }^{33}$

During the first wave of the COVID-19 epidemic in Spain, social services were also overwhelmed and many local associations had to help to meet essential and home care needs to ensure a minimum level of welfare for large sections of the population. ${ }^{34}$ The COVID-19 pandemic has highlighted the need to reinforce local administrations and to continue providing social services and programmes for engaging and supporting patients, especially the most vulnerable such as older adults, during this difficult time of physical distancing and stay-at-home orders. ${ }^{35}$ Within an increased demand for these services in such a short period, stable networks between local administrations and community-based organisations in the delivery of essential social services would improve equitable access to these services. ${ }^{36}$

Patients and their families were isolated at their home suffering a new, severe and unknown illness and seeing the numbers of cases and deaths increasing daily. These stressful situations could explain why patients with COVID-19 feel depressed more often than the uninfected population. Many authors have studied the psychological impact of COVID-19 in both the general population ${ }^{37}$ and the patients, ${ }^{38-42}$ finding an increased level of mental distress. Depression is one of the psychiatric outcomes most prevalent in those studies. Some researchers also found higher rates of depression in patients who experienced COVID-19 compared with confined uninfected people. $^{43}$

Patients with COVID-19 seem to be more cautious than the general population in taking preventive measures, as they reported always wearing a mask 1.5 times more frequently than the uninfected population. They also reported having stayed at home since the start of the lockdown 3.2 times more frequently than the uninfected population. Fear, stress and depression suffered by patients with COVID-19 could explain these better preventive behaviours after the disease episode.

Knowledge about the disease could also have prompted better preventive behaviour. The population's knowledge about COVID-19 was in general good in Spain during the study period, but there were some significant differences with regard to knowledge about disease symptoms, transmission and prevention between COVID-19 cases and the uninfected population. As could be expected with a new disease, cases could have better knowledge about symptoms and modes of transmission than the uninfected population. As there were no differences in disease risk perception and severity, having better knowledge about the disease could also explain a better preventive behaviour. It would be interesting to determine whether this preventive behaviour among the cases is maintained over time.

This study has some limitations. The survey was mainly completed by highly educated people and therefore findings might not be generalisable. Women were also more represented than men and COVID-19 cases were based on the diagnosis reported by the respondents. There might also be some bias due to the use of WhatsApp within the Spanish population, especially among people over 74 years old. However, the advantage of the survey tool was the potential for rapid, accessible, multi-platform deployments, as well as the possibility of obtaining a large sample in the shortest time possible in order to assess how the population managed the disease at home just before the end of the lockdown.

\section{CONCLUSIONS}

COVID-19 cases found it hard to comply with the recommended home isolation conditions, which different age groups followed in different ways. Our study also found that cases were better informed about COVID-19 symptoms and transmission and showed better preventive behaviour than the uninfected population; however, they also felt depressed more often.

Social and health services must be reinforced and be ready to meet the care needs of populations during the different waves or in future epidemics. It is also important to develop a communication strategy aimed at people who are experiencing the disease while isolated in their homes in order to reduce their distress.

\section{Author affiliations}

${ }^{1}$ Centro Nacional de Medicina Tropical, Instituto de Salud Carlos III, Madrid, Spain ${ }^{2}$ Red de Investigación Colaborativa en Enfermedades Tropicales, Madrid, Spain

${ }^{3}$ Unidad de Investigación en Salud Digital, Instituto de Salud Carlos III, Madrid, Spain ${ }^{4}$ Departamento de Ciencias Sociosanitarias, Universidad de Murcia, Murcia, Spain ${ }^{5}$ Centro Nacional de Epidemiología, Instituto de Salud Carlos III, Madrid, Spain ${ }^{6}$ Red de Investigación en Servicios de Salud en Enfermedades Crónicas, Madrid, Spain

${ }^{7}$ Instituto Universitario de Estudios de Género, Universidad Carlos III de Madrid Campus de Leganes, Leganes, Spain

${ }^{8}$ Departamento de Biotecnología y Biomedicina, Universidad de Alcalá de Henares, Madrid, Spain

Acknowledgements The authors would like to thank the study participants for having understood the interest of this study and volunteering to answer the survey.

Contributors MR-B and $\mathrm{ABe}$ were responsible for the conception and design of the study. MP-C, MJDT-D, ABu and AM designed and implemented the telematics resources. MR-B, AA and IMF performed the statistical analysis. MR-B drafted the initial version of the manuscript. All authors (MR-B, MF, CR-B, MJF, AA, IMF, ABu, MP-C, MJDT-D, ABe and AM) contributed to data interpretation, critically reviewed the first draft and approved the final version. The corresponding author attests that all listed authors meet the authorship criteria and that no others meeting the criteria have been omitted. 
Funding This work was supported by Instituto de Salud Carlos III through the National Tropical Diseases Research Network (RD16CIII/003/001RICET). The funders had no role in study design or in the collection, analysis and interpretation of data, or the decision to submit the article for publication.

Competing interests None declared.

\section{Patient consent for publication Obtained.}

Ethics approval This study was approved by the Ethics Committee of the Spanish National Health Institute, Carlos III (CEI PI 43_2020).

Provenance and peer review Not commissioned; externally peer reviewed.

Data availability statement All data relevant to the study are included in the article or uploaded as supplementary information.

Supplemental material This content has been supplied by the author(s). It has not been vetted by BMJ Publishing Group Limited (BMJ) and may not have been peer-reviewed. Any opinions or recommendations discussed are solely those of the author(s) and are not endorsed by BMJ. BMJ disclaims all liability and responsibility arising from any reliance placed on the content. Where the content includes any translated material, BMJ does not warrant the accuracy and reliability of the translations (including but not limited to local regulations, clinical guidelines, terminology, drug names and drug dosages), and is not responsible for any error and/or omissions arising from translation and adaptation or otherwise.

Open access This is an open access article distributed in accordance with the Creative Commons Attribution Non Commercial (CC BY-NC 4.0) license, which permits others to distribute, remix, adapt, build upon this work non-commercially, and license their derivative works on different terms, provided the original work is properly cited, appropriate credit is given, any changes made indicated, and the use is non-commercial. See: http://creativecommons.org/licenses/by-nc/4.0/.

\section{ORCID iD}

María Romay-Barja http://orcid.org/0000-0002-0177-6885

\section{REFERENCES}

1 Zhu N, Zhang D, Wang W, et al. A novel coronavirus from patients with pneumonia in China, 2019. N Engl J Med 2020;382:727-33.

2 Wang D, Hu B, Hu C, et al. Clinical characteristics of 138 hospitalized patients with 2019 novel coronavirus-infected pneumonia in Wuhan, China. JAMA 2020;323:1061-9.

3 Who novel coronavirus (2019-nCoV) situation report - 22, 11 February, 2020. Available: https://www.who.int/docs/default-source/ coronaviruse/situation-reports/20200211-sitrep-22-ncov.pdf2020

4 WHO Director-General's opening remarks at the media briefing on COVID-19 - 11 March, 2020. Available: https://www.who.int/directorgeneral/speeches/detail/who-director-general-s-opening-remarks-atthe-media-briefing-on-covid-19-11-march-2020

5 Galluccio F, Ergonenc T, Garcia Martos A, et al. Treatment algorithm for COVID-19: a multidisciplinary point of view. Clin Rheumatol 2020;39:2077-84.

6 Liu Y, Mao B, Liang S, et al. Association between age and clinical characteristics and outcomes of COVID-19. Eur Respir J 2020;55:2001112.

7 Presidencia Mdela. Relaciones Con LAS Cortes Y Memoria Democrática. real Decreto 463/2020, de 14 de marzo, POR El que se declara El estado de alarma para La gestión de la situación de crisis sanitaria ocasionada POR El COVID-19. Bol. Of. Estado BOE 2020. Available https://boe.es/buscar/act.php? id=BOE-A-2020-3692

8 Informe no 27. Situación de COVID-19 en España a 30 de abril de 2020.pdf. Available: https://www.isciii.es/QueHacemos/Servicios/ VigilanciaSaludPublicaRENAVE/EnfermedadesTransmisibles/ Documents/INFORMES/Informes\%20COVID-19/Informe\%20n\% c2\%ba\%2027.\%20Situaci\%c3\%b3n\%20de\%20COVID-19\% 20en\%20Espa\%c3\%b1a\%20a\%2030\%20de\%20abril\%20de\% 202020.pdf

9 Pollán M, Pérez-Gómez B, Pastor-Barriuso R, et al. Prevalence of SARS-CoV-2 in Spain (ENE-COVID): a nationwide, population-based seroepidemiological study. Lancet 2020;396:535-44.

10 Novel coronavirus (SARS-CoV-2) - Discharge criteria for confirmed COVID-19 cases [Internet]. Eur Cent Dis Prev Control 2020. Available https://www.ecdc.europa.eu/en/publications-data/novel-coronavirussars-cov-2-discharge-criteria-confirmed-covid-19-cases
11 Chan EYY, Gobat N, Kim JH, et al. Informal home care providers: the forgotten health-care workers during the COVID-19 pandemic. Lancet 2020;395:1957-9.

12 Who home care for patients with suspected or confirmed COVID-19 and management of their contacts. Available: https://www.who.int/ publications/i/item/home-care-for-patients-with-suspected-novelcoronavirus-(ncov)-infection-presenting-with-mild-symptoms-andmanagement-of-contacts

13 Sehgal AR, Himmelstein DU, Woolhandler S. Feasibility of separate rooms for home isolation and quarantine for COVID-19 in the United States. Ann Intern Med 2021;174:127-9.

14 Levin SR, Gitkind Al, Bartels MN. Effect of the COVID-19 pandemic on Postacute care decision making. Arch Phys Med Rehabil 2021;102:323-30.

15 Hernández-Padilla JM, Granero-Molina J, Ruiz-Fernández MD, et al. Design and psychometric analysis of the COVID-19 prevention, recognition and Home-Management self-efficacy scale. Int J Environ Res Public Health 2020;17. doi:10.3390/ijerph17134653. [Epub ahead of print: 2806 2020].

16 Haroon S, Chandan JS, Middleton J. Covid-19: breaking the chain of household transmission. BMJ 2020;370:m3181.

17 Dong E, Du H, Gardner L. An interactive web-based dashboard to track COVID-19 in real time. Lancet Infect Dis 2020;20:533-4.

18 Gong W, Taighoon Shah M, Firdous S, et al. Comparison of three rapid household survey sampling methods for vaccination coverage assessment in a peri-urban setting in Pakistan. Int $\mathrm{J}$ Epidemiol 2019;48:583-95.

19 Geldsetzer P. Use of rapid online surveys to assess people's perceptions during infectious disease outbreaks: a cross-sectional survey on COVID-19. J Med Internet Res 2020;22:e18790.

20 Quah SR, Hin-Peng L. Crisis prevention and management during SARS outbreak, Singapore. Emerg Infect Dis 2004;10:364-8.

21 Tang CS-kum, Wong C-yan, Wong C. Factors influencing the wearing of facemasks to prevent the severe acute respiratory syndrome among adult Chinese in Hong Kong. Prev Med 2004;39:1187-93.

22 Instituto Nacional de Estadística. Encuesta sobre Equipamiento $Y$ Uso de Tecnologías de Información Y Comunicación en Los Hogares Año, 2020. Available: https://www.ine.es/prensa/tich 2020.pdf [Accessed 16 November 2020].

23 Madewell ZJ, Yang Y, Longini IM, et al. Household transmission of SARS-CoV-2: a systematic review and meta-analysis. JAMA Netw Open 2020;3:e2031756.

24 Rozenfeld Y, Beam J, Maier $\mathrm{H}$, et al. A model of disparities: risk factors associated with COVID-19 infection. Int $J$ Equity Health 2020;19:126.

25 Rodríguez-Barranco M, Rivas-García L, Quiles JL, et al. The spread of SARS-CoV-2 in Spain: hygiene habits, sociodemographic profile, mobility patterns and comorbidities. Environ Res 2021;192:110223.

26 Stawicki SP, Kalra S, Jones C, et al. Comorbidity polypharmacy score and its clinical utility: a pragmatic practitioner's perspective. $J$ Emerg Trauma Shock 2015;8:224-31.

27 Pastor-Barriuso R, Pérez-Gómez B, Hernán MA, et al. Infection fatality risk for SARS-CoV-2 in community dwelling population of Spain: nationwide seroepidemiological study. BMJ 2020;371:m4509.

28 Self WH, Semler MW, Leither LM, et al. Effect of hydroxychloroquine on clinical status at 14 days in hospitalized patients with COVID-19: a randomized clinical trial. JAMA 2020;324:2165-76.

29 Cartenì A, Di Francesco L, Martino M. How mobility habits influenced the spread of the COVID-19 pandemic: results from the Italian case study. Sci Total Environ 2020;741:140489.

$30 \mathrm{Hu}$ X, Ni W, Wang Z, et al. The distribution of SARSCoV-2 contamination on the environmental surfaces during incubation period of COVID-19 patients. Ecotoxicol Environ Saf 2021;208:111438.

31 et alRuíz-Roso MB, de Carvalho Padilha P, Matilla-Escalante DC. Changes of Physical Activity and Ultra-Processed Food Consumption in Adolescents from Different Countries during Covid-19 Pandemic: An Observational Study. Nutrients;12. Available: https://www.ncbi.nlm.nih.gov/pmc/articles/PMC7468997/

32 Las colas del hambre: 600.000 atendidos más en Bancos de Alimentos desde La pandemia. Econ. Digit 2021. Available https://www.economiadigital.es/politica/las-colas-del-hambre600-000-atendidos-mas-en-bancos-de-alimentos-desde-lapandemia.html

33 Baumer Y, Farmer N, Premeaux TA, et al. Health disparities in COVID-19: addressing the role of social determinants of health in immune system dysfunction to turn the tide. Front Public Health 2020;8:559312.

34 Muñoz-Moreno R, Chaves-Montero A, Morilla-Luchena A, et al. COVID-19 and social services in Spain. PLoS One 2020;15:e0241538. 
35 Smith ML, Steinman LE, Casey EA. Combatting social isolation among older adults in a time of physical distancing: the COVID-19 social connectivity paradox. Front Public Health 2020;8:403.

36 Belso-Martínez JA, Mas-Tur A, Sánchez M, et al. The COVID-19 response system and collective social service provision. strategic network dimensions and proximity considerations. Serv Bus 2020:14:387-411.

37 Salari N, Hosseinian-Far A, Jalali R, et al. Prevalence of stress, anxiety, depression among the general population during the COVID-19 pandemic: a systematic review and meta-analysis. Global Health 2020;16:57.

38 Parker C, Shalev D, Hsu I, et al. Depression, anxiety, and acute stress disorder among patients hospitalized with coronavirus disease 2019: a prospective cohort study. Psychosomatics 2020 doi:10.1016/j.psym.2020.10.001. [Epub ahead of print: 10 Oct 2020].
39 Taquet M, Luciano S, Geddes JR, et al. Bidirectional associations between COVID-19 and psychiatric disorder: retrospective cohort studies of 62354 COVID-19 cases in the USA. Lancet Psychiatry 2021;8:130-140.

40 Mazza MG, De Lorenzo R, Conte C, et al. Anxiety and depression in COVID-19 survivors: role of inflammatory and clinical predictors. Brain Behav Immun 2020;89:594-600.

41 Carvalho PMdeM, Moreira MM, de Oliveira MNA, et al. The psychiatric impact of the novel coronavirus outbreak. Psychiatry Res 2020;286:112902.

42 Şahan E, Ünal SM, Kırpınar İsmet. Can we predict who will be more anxious and depressed in the COVID-19 ward? J Psychosom Res 2021;140:110302.

43 Zhang J, Lu H, Zeng $\mathrm{H}$, et al. The differential psychological distress of populations affected by the COVID-19 pandemic. Brain Behav Immun 2020;87:49-50. 